\title{
Formação in-situ ou adição de espinélio pré-formado: o que é melhor para concretos refratários aluminosos?
}

\section{(In-situ formation or pre-formed spinel addition: which one is better for high alumina refractory castable?)}

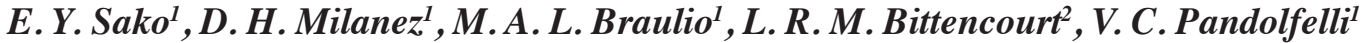 \\ ${ }^{1}$ Grupo de Engenharia de Microestrutura de Materiais - GEMM, Departamento de Engenharia de Materiais \\ Universidade Federal de S. Carlos, Rod. Washington Luiz, km 235, C.P. 676, S. Carlos, SP 13565-905 \\ ${ }^{2}$ Magnesita S.A., Centro de Pesquisas e Desenvolvimento - CPqD, Praça Louis Ensch 240, Contagem, MG \\ vicpando@power.ufscar.br
}

\begin{abstract}
Resumo
O desenvolvimento do setor siderúrgico está intimamente relacionado aos progressos obtidos na produção de refratários. Nas panelas de siderurgia, uma das principais exigências são revestimentos que apresentem excelentes propriedades termomecânicas para suportar os ciclos térmicos, além de uma boa resistência à corrosão e à penetração de escórias básicas. Em concretos refratários aluminosos, essas características são obtidas pela incorporação de espinélio pré-formado ou pela espinelização in-situ, onde nesta segunda rota os óxidos de alumínio e de magnésio reagem entre si em temperaturas elevadas durante o uso do revestimento. $\mathrm{O}$ objetivo do presente trabalho foi a análise comparativa e sistêmica destas duas classes de concretos aluminosos espinelizados, visando-se avaliar as diferenças em suas propriedades principalmente após sinterização. Foi observado que os concretos contendo espinélio in-situ apresentaram propriedades mecânicas superiores após queima a $1500{ }^{\circ} \mathrm{C}$, além de maior variação dimensional. Adicionalmente, o efeito da adição de frações grosseiras de espinélio pré-formado indicou a influência dos agregados sob a estabilidade volumétrica de concretos espinelizados in-situ.

Palavras-chave: refratários, espinélio, agregados.
\end{abstract}

\begin{abstract}
Considering that developments on refractories performance are of utmost importance to the steel industry advances, thermomechanical properties and the corrosion and slag penetration resistance of the lining material are constantly being improved to extend steel ladle working life. These benefits could be attained in high alumina refractory castable by adding pre-formed spinel or magnesia, in order to result in the latter condition in in-situ spinel during the first use of the lining. The objective of the present work was to compare between high alumina castables with pre-formed or in situ spinel in order to verify their main properties differences. In addition, pre-formed spinel was used as aggregate replacing tabular alumina in alumina-magnesia compositions to analyze the effect of coarse particles in the expansion behavior of this type of castable. The results showed higher expansion and better mechanical performance for castables with in-situ spinel after firing at $1500{ }^{\circ} \mathrm{C}$. Also, the use of different aggregates in the same composition resulted in distinct expansion values.
\end{abstract}

Keywords: refractories, spinel, aggregates.

\section{INTRODUÇÃO}

Em decorrência das condições agressivas durante o processo de refino secundário do aço, os refratários das panelas de siderurgia são hoje resultado de intensa pesquisa, visando aumentar sua vida útil e atender as exigências de maior produtividade da indústria siderúrgica [1]. Para tal, materiais com propriedades termomecânicas superiores e de alta resistência à corrosão e à penetração de escória básica são necessários [2].

Neste contexto, situam-se os concretos refratários aluminosos contendo espinélio no sistema alumina-magnésia, que apresentam estabilidade química e estrutura cristalina propícia para a acomodação de íons deletérios da escória
[3]. A incorporação de espinélio pode ser alcançada por duas metodologias distintas: como matéria-prima pré-formada ou por meio da reação in-situ entre os óxidos de alumínio e magnésio em temperaturas próximas a $1200^{\circ} \mathrm{C}$ [4].

As principais vantagens de um concreto espinelizado in-situ são suas melhores propriedades químicas devido à formação de um espinélio finamente disperso pela matriz, além da densificação e tenacificação da matriz decorrente do caráter expansivo da reação de espinelização $[5,6]$. No entanto, essa expansão pode causar microtrincamentos e resultar na deterioração das propriedades do concreto, caso não seja controlada [7]. Além disso, neste tipo de material, também é necessário atentar aos problemas ocasionados durante o processamento devido à hidratação da magnésia, 
que também é expansiva e muitas vezes destrutiva [5]. Por outro lado, os concretos aluminosos pré-espinelizados são estáveis volumetricamente e não possuem magnésia livre, além de já conterem espinélio em sua composição em temperaturas inferiores a de sua formação. A desvantagem principal é o elevado custo associado ao grande consumo de energia necessária para a fabricação de espinélios préformados.

Considerando-se tais aspectos, um dos objetivos do presente trabalho foi, por meio de ensaios de resistência mecânica, de sinterabilidade assistida e resistência à fluência, avaliar as principais diferenças entre as propriedades dessas duas classes de concretos refratários, dada a sua relevância como material de revestimento das panelas siderúrgicas [8].

Outro fator que afeta o comportamento desses materiais é o tipo e a inércia dos agregados refratários. Alguns estudos $[9,10]$ consideram apenas partículas finas quando estudam tais reações, uma vez que as matérias-primas da matriz possuem maior reatividade. No entanto, também já foi claramente demonstrado que diferentes tipos de agregados em concretos contendo a mesma matriz levam a caminhos distintos de reações durante a sinterização [11]. De acordo com estas informações, neste trabalho também foi avaliado o efeito da presença de agregados de espinélio pré-formado em substituição às aluminas tabulares no comportamento expansivo de um concreto do sistema alumina-magnésia.

\section{MATERIAIS E MÉTODOS}

Para a comparação entre os concretos contendo espinélio pré-formado e os concretos espinelizados in-situ foram formuladas duas composições: alumina-espinélio (AE) e alumina-magnésia (AM). Em ambas, foram utilizadas aluminas tabulares como agregados $(\mathrm{d} \leq 6 \mathrm{~mm}$, Almatis, Alemanha), cimento de aluminato de cálcio como ligante (Secar 71, Kerneos, França) e microssílica (971 U, Elkem, Noruega). Na composição AE foi adicionado espinélio préformado (AR78, 78\%-p de alumina, $\mathrm{d} \leq 0,5 \mathrm{~mm}$, Almatis, Alemanha) e na composição AM incorporou-se sínter de magnésia $\left(95 \%\right.$ de $\mathrm{MgO}, \mathrm{CaO} / \mathrm{SiO}_{2}=0,36, \mathrm{~d} \leq 45 \mu \mathrm{m}$, Magnesita S.A., Brasil) e alumina reativa (CL 370, Almatis, Alemanha). Nos dois casos, projetou-se um teor de espinélio igual a 21\%-p. Como aditivo dispersante foi utilizado um policarboxilato (Bayer, Alemanha).

Para análise do efeito dos agregados refratários, utilizaram-se as composições alumina-magnésia (AM) e espinélio-magnésia (EM), onde essa última difere da primeira somente em relação à presença de agregados de espinélio pré-formado (MA76, 76\%-p de alumina, d $\leq 4,75 \mathrm{~mm}$, Magnesita S.A., Brasil) em substituição às aluminas tabulares. As diferentes composições avaliadas são apresentadas na Tabela I.

Os teores de água utilizados durante o processamento foram 3,9\%-p para a composição AM e 4,1\%-p para as composições AE e EM. Esses teores foram pré-definidos para que os concretos alcançassem um mínimo de fluidez vibrada de $80 \%$ logo após mistura, garantindo-se
Tabela I - Formulações dos concretos estudados.

[Table 1 - Castables compositions.]

\begin{tabular}{lccc}
\hline \multicolumn{1}{c}{ Matéria-prima } & AE & AM & EM \\
& $\%-p$ & $\%-p$ & $\%-p$ \\
\hline Alumina Tabular & 62 & 62 & - \\
$(6 \mathrm{~mm} \leq \mathrm{d} \leq 0,2 \mathrm{~mm})$ & 10 & 18 & 18 \\
Alumina Tabular $(\mathrm{d} \leq 0,2 \mathrm{~mm})$ & - & - & 62 \\
Espinélio MA76 $(\mathrm{d} \leq 4,75 \mathrm{~mm})$ & - & - & - \\
Espinélio AR78 $(\mathrm{d} \leq 0,5 \mathrm{~mm})$ & 21 & 6 & 6 \\
Sínter de MgO $(\mathrm{d} \leq 45 \mu \mathrm{m})$ & - & 7 & 7 \\
Alumina Reativa CL 370 & - & 6 & 6 \\
Cimento de Aluminato de Cálcio & 6 & 1 & 1 \\
Secar 71 & 1 & 1 & \\
Microssílica 971 U & & &
\end{tabular}

moldagens adequadas.

Corpos de prova para ensaios mecânicos e medidas de variação linear dimensional (VLD) após queima em temperaturas elevadas foram moldados na forma de barras de dimensões $25 \times 25 \times 150 \mathrm{~mm}^{3}$, seguido de cura por $24 \mathrm{~h}$ a $50{ }^{\circ} \mathrm{C}$, secagem por $24 \mathrm{~h}$ a $110^{\circ} \mathrm{C}$, calcinação por $5 \mathrm{~h}$ a $600{ }^{\circ} \mathrm{C}$ e queima a $1{ }^{\circ} \mathrm{C} / \mathrm{min}$ a 1150,1300 e $1500{ }^{\circ} \mathrm{C}$ por $5 \mathrm{~h}$. O módulo de ruptura a frio foi obtido por meio de ensaio de flexão três pontos em uma máquina de ensaios universais MTS 810 (MTS Systems Corp., EUA), segundo a norma C133-94 da ASTM. A VLD foi obtida pelas medidas dos comprimentos das barras antes e após queima. A porosidade aparente foi obtida pelo método de Arquimedes com imersão em querosene segundo a norma C830 da ASTM.

Para os ensaios de fluência e expansão assistida, foram moldados corpos de prova no formato cilíndrico de acordo com a norma DIN 51053, seguido de cura a $50^{\circ} \mathrm{C}$ por $24 \mathrm{~h}$, secagem a $110^{\circ} \mathrm{C}$ por $24 \mathrm{~h}$ e calcinação por $5 \mathrm{~h}$ a $600{ }^{\circ} \mathrm{C}$. Os ensaios de fluência foram realizados em um equipamento de refratariedade sob carga RUL 421 E (Netzsch, Alemanha), onde o corpo de prova previamente queimado por $24 \mathrm{~h}$ a $1550{ }^{\circ} \mathrm{C}$ fica sujeito a uma carga de $0,2 \mathrm{MPa}$ e temperatura constante de $1450{ }^{\circ} \mathrm{C}$ por $24 \mathrm{~h}$. Os ensaios de sinterabilidade assistida foram realizados no mesmo equipamento, onde os corpos de prova sob uma carga de $0,02 \mathrm{MPa}$ foram aquecidos até $1500{ }^{\circ} \mathrm{C}$ a uma taxa de $3{ }^{\circ} \mathrm{C} / \mathrm{min}$, seguida de um patamar de $5 \mathrm{~h}$ nesta temperatura. Amostras sinterizadas a $1500{ }^{\circ} \mathrm{C}$ foram avaliadas por microscopia eletrônica de varredura em um equipamento SEM S-510 (Hitachi, Japão).

\section{RESULTADOS E DISCUSSÃO}

A primeira variável analisada neste estudo foi o tipo de incorporação de espinélio: pré-formado (AE) ou in-situ (AM). As curvas de sinterabilidade assistida destes materiais podem ser avaliadas na Fig. 1.

A composição $\mathrm{AM}$ apresentou expansão térmica total superior à da composição $\mathrm{AE}$, algo esperado devido à 


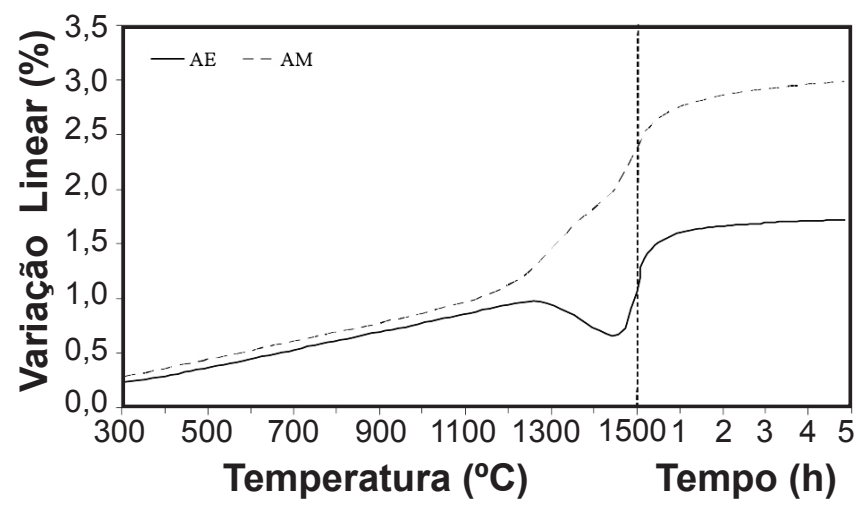

Figura 1: Curvas de sinterabilidade assistida das composições alumina-espinélio (AE) e alumina-magnésia (AM).

[Figure 1: Expansion behavior of alumina-spinel (AE) and alumina-magnesia (AM) castables.]

espinelização in-situ. No entanto, a composição AE também apresentou uma variação linear considerável, resultado de outra reação expansiva em temperaturas próximas a $1450{ }^{\circ} \mathrm{C}$, a ser destacada a seguir.

Analisando-se a taxa de variação linear desses concretos (Fig. 2), dois picos significativos podem ser identificados ao longo das curvas. O primeiro em torno de $1300{ }^{\circ} \mathrm{C}$ está associado à formação de espinélio in-situ [6]. Entre 1400 e $1500{ }^{\circ} \mathrm{C}$, outro aumento na taxa de variação linear pode ser observado nas duas composições. Este segundo pico na taxa de expansão está relacionado à formação de $\mathrm{CA}_{6}$ $\left(\mathrm{CaO} .6 \mathrm{Al}_{2} \mathrm{O}_{3}\right)$, uma fase refratária que se forma por meio da reação entre alumina e o $\mathrm{CaO}$ presente no cimento $[5,6]$. Na Fig. 3 é possível observar os grãos de $\mathrm{CA}_{6}$ presentes na microestrutura dos dois concretos após queima a $1500{ }^{\circ} \mathrm{C}$ por $5 \mathrm{~h}$.

A presença da fase $\mathrm{CA}_{6}$, pelo seu formato acicular, pode resultar em aumento de resistência mecânica do material devido às conexões geradas entre os agregados e a matriz. Porém, assim como ocorre na espinelização in-situ, uma expansão não controlada pode resultar em

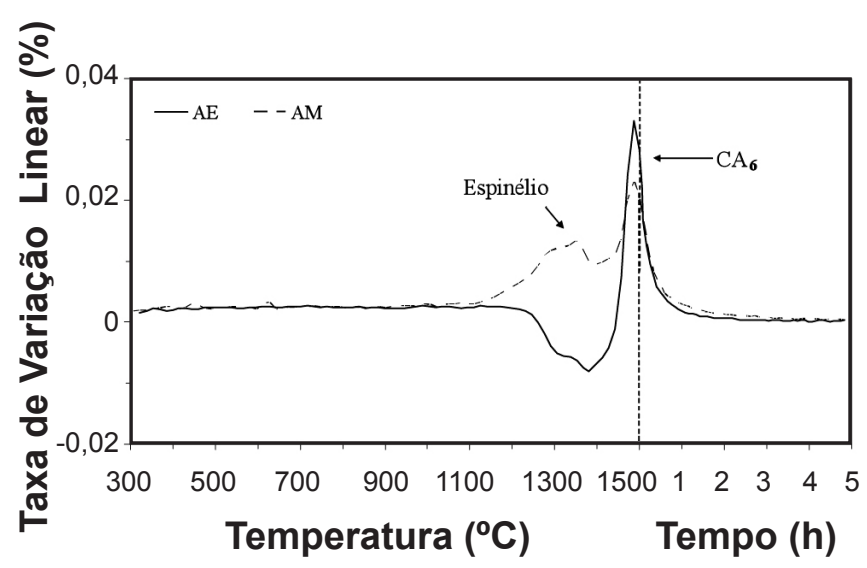

Figura 2: Taxa de variação linear das composições aluminaespinélio (AE) e alumina-magnésia (AM).

[Figure 2: Expansion rate of alumina-spinel $(A E)$ and aluminamagnesia (AM) castables.] efeitos indesejáveis, devido à deterioração das propriedades mecânicas pela formação de microtrincas e conseqüente aumento de porosidade. Este é o caso da composição AE, que apresenta uma redução de resistência mecânica a frio de 1300 para $1500{ }^{\circ} \mathrm{C}$, bem como um aumento de porosidade aparente, como pode ser observado na Tabela II.

Devido a este efeito expansivo do $\mathrm{CA}_{6}$, o controle do teor de cimento de aluminato de cálcio é fundamental para se obter uma expansão "engenheirada" que não ocasione danos ao concreto refratário $[5,6]$. Adicionalmente, a presença de microssílica afeta significativamente tal reação [12].
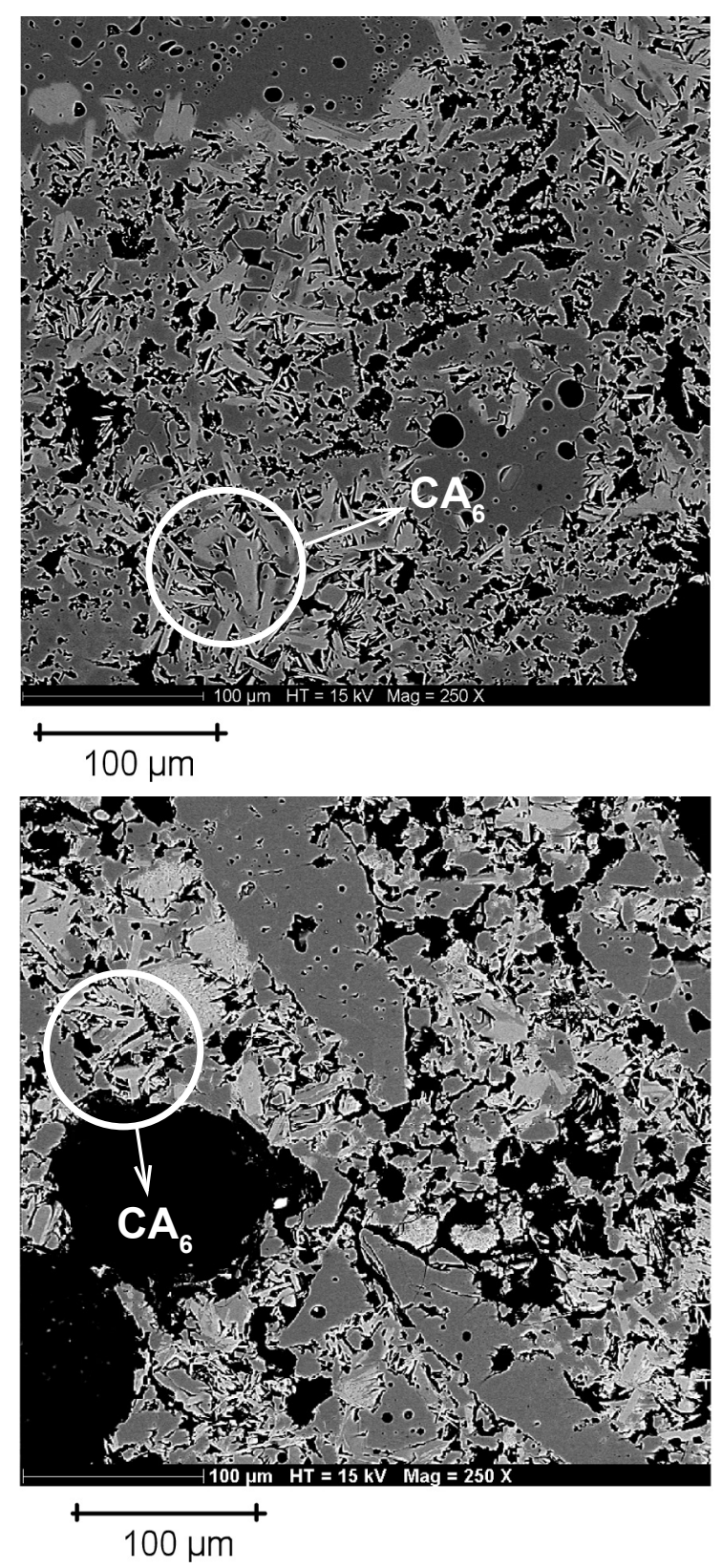

Figura 3: Micrografias obtidas por microscopia eletrônica de varredura após queima por $5 \mathrm{~h}$ a $1500{ }^{\circ} \mathrm{C}$ das composições (a) alumina-magnésia (AM) e (b) alumina-espinélio (AE).

[Figure 3: SEM microstructural features after firing for $5 \mathrm{~h}$ at $1500{ }^{\circ} \mathrm{C}$ of (a) alumina-magnesia (AM) and (b) alumina-spinel (AE) castables.] 
A Fig. 4 apresenta os resultados dos ensaios de fluência das composições AE e AM, onde se nota um comportamento de deformação linear semelhante em ambas as composições. A deformação obtida é decorrência da presença de matériasprimas que resultam em fases de baixo ponto de fusão no sistema $\mathrm{Al}_{2} \mathrm{O}_{3}-\mathrm{SiO}_{2}-\mathrm{CaO}$, como a guelenita e/ou anortita, interferindo significantemente no comportamento de fluência

Tabela II - Porosidade aparente, resistência mecânica e VLD em função da temperatura de queima para as composições alumina-espinélio (AE) e alumina-magnésia (AM).

[Table II - Apparent porosity, mechanical strength and permanent linear expansion (PLE) with the firing temperature for alumina-spinel ( $A E)$ and alumina-magnesia (AM) castables.]

\begin{tabular}{ccccc}
\hline \multirow{2}{*}{ Composição } & $\begin{array}{c}\text { Temperatura } \\
\text { de queima } \\
\left({ }^{\circ} \mathrm{C}\right)\end{array}$ & $\begin{array}{c}\text { Porosidade } \\
\text { aparente } \\
(\%)\end{array}$ & $\begin{array}{c}\text { Resistência } \\
\text { mecânica } \\
(\mathrm{MPa})\end{array}$ & $\begin{array}{c}\text { VLD } \\
(\%)\end{array}$ \\
\hline \multirow{4}{*}{$\mathrm{AE}$} & 1150 & $16,8 \pm 0,8$ & $17,1 \pm 1,1$ & $-0,03$ \\
& 1300 & $16,4 \pm 0,9$ & $26,6 \pm 2,0$ & $-0,06$ \\
& 1500 & $20,0 \pm 0,3$ & $24,6 \pm 1,2$ & 1,60 \\
\hline \multirow{3}{*}{$\mathrm{AM}$} & 1150 & $15,7 \pm 0,3$ & $24,8 \pm 0,8$ & 0,17 \\
& 1300 & $17,8 \pm 0,3$ & $27,1 \pm 1,3$ & 0,94 \\
& 1500 & $23,1 \pm 0,4$ & $29,7 \pm 0,7$ & 2,56 \\
\hline
\end{tabular}

dos concretos refratários [13].

Outro parâmetro analisado neste estudo foi a substituição de agregados de alumina tabular por outros de espinélios pré-formados eletrofundidos em uma composição do sistema alumina-magnésia. O objetivo foi a comparação dos dois tipos de concretos com mesma matriz e diferentes agregados (alumina-magnésia - AM e espinélio-magnésia EM). A Fig. 5 ilustra as curvas de sinterabilidade assistida e a Fig. 6 apresenta a taxa de variação linear dessas duas composições, podendo-se observar que, apesar de ambas as composições sofrerem as mesmas reações de transformação

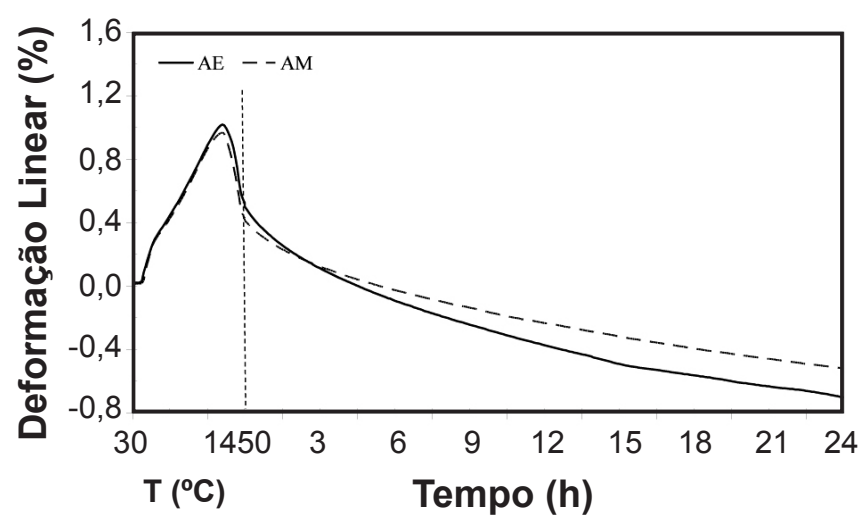

Figura 4: Curvas dos ensaios de fluência das composições aluminaespinélio (AE) e alumina-magnésia (AM).

[Figure 4: Creep behavior of alumina-spinel (AE) and aluminamagnesia (AM) castables.]

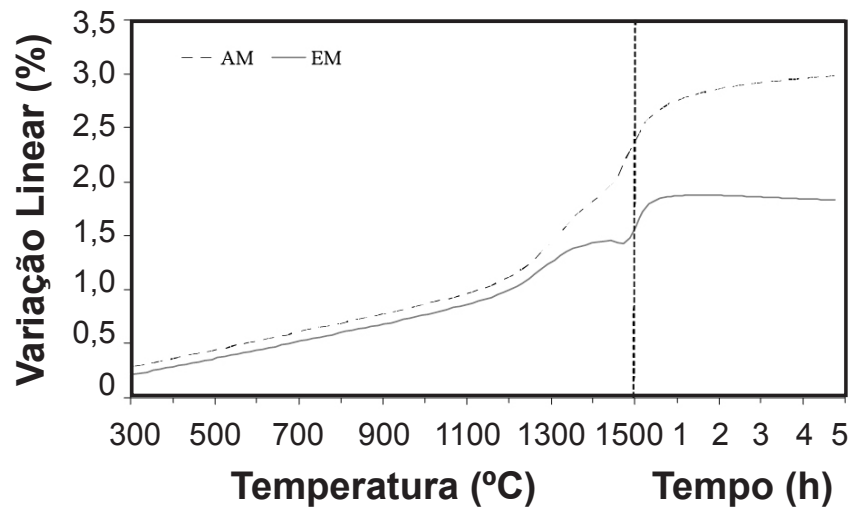

Figura 5: Curvas de sinterabilidade assistida das composições alumina-magnésia (AM) e espinélio-magnésia (EM).

[Figure 5: Expansion behavior of alumina-magnesia (AM) and spinel-magnesia (EM) castables.]

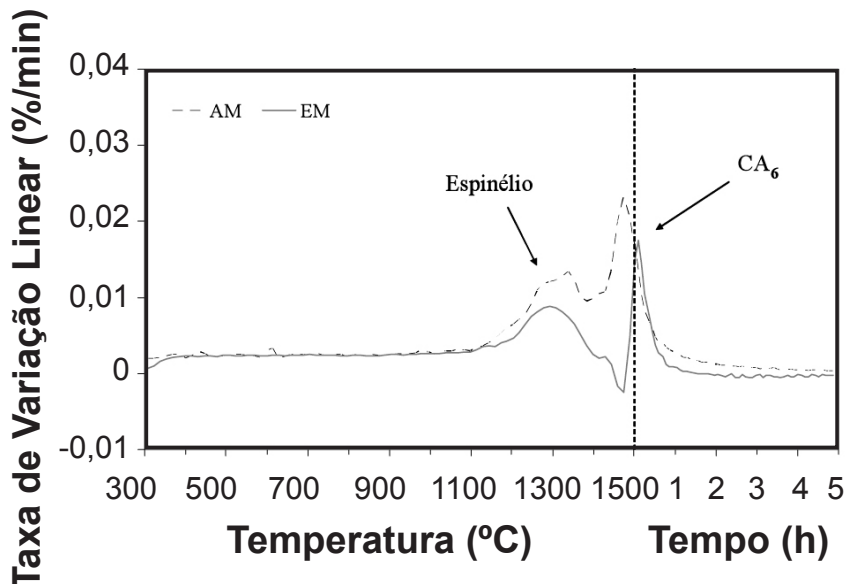

Figura 6: Taxa de variação linear das composições aluminamagnésia (AM) e espinélio-magnésia (EM).

[Figure 6: Expansion rate of alumina-magnesia (AM) and spinelmagnesia (EM) castables.]

de fases em sua matriz, seu comportamento expansivo é distinto, principalmente após $1400{ }^{\circ} \mathrm{C}$. Tal resultado está possivelmente associado ao menor teor de $\mathrm{CA}_{6}$ nos concretos EM, já que para formação desta fase há necessidade de um alto teor de alumina disponível [14]. Como a alumina na matriz é consumida na formação de espinélio, faz-se necessário uma quantidade adicional deste óxido para formação de $\mathrm{CA}_{6}$. Na composição AM, os agregados de alumina tabular suprem esta demanda, enquanto na composição EM, o CA 6 só pode ser formado na matriz, devido à impossibilidade de reação com os agregados de espinélio. Dessa forma, confirma-se mais uma vez que os agregados refratários não são totalmente inertes em composições refratarias, influenciando na sua estabilidade volumétrica.

\section{CONCLUSÕES}

Os resultados obtidos na comparação de concretos refratários aluminosos pré-espinelizados e espinelizados in-situ indicaram a maior estabilidade volumétrica do 
concreto AE. No entanto, apesar de uma menor porosidade aparente, suas propriedades mecânicas foram um pouco inferiores à composição AM. Além disso, os resultados também mostraram que os concretos ligados por cimento de aluminato de cálcio são afetados pela geração de uma fase de alta refratariedade: o $\mathrm{CA}_{6}$. Porém, assim como no caso da reação de espinelização, a formação de $\mathrm{CA}_{6}$ não controlada pode causar danos ao material devido a uma expansão excessiva, tais como aqueles verificados para a resistência mecânica a frio após queima a $1500{ }^{\circ} \mathrm{C}$ da composição AE. Os resultados de fluência mostraram proximidade das duas composições, com deformações significativas, em decorrência da possível presença de fases de baixo ponto de fusão do sistema $\mathrm{Al}_{2} \mathrm{O}_{3}-\mathrm{SiO}_{2}-\mathrm{CaO}$.

Os concretos com mesma matriz e agregados distintos resultaram em diferentes comportamentos expansivos, mesmo apresentando as mesmas reações de transformação de fases em sua matriz. Isto ocorreu devido à menor formação de $\mathrm{CA}_{6}$ na composição EM pela ausência de grãos de alumina tabular. Este fato contrapõe resultados que reportam que os agregados são inertes em uma composição refratária, criando uma nova alternativa de controle da expansão de concretos refratários espinelizados in-situ sem alterar sua matriz.

\section{AGRADECIMENTOS}

Ao CNPq, à FIRE e à Magnesita S.A. pelo suporte na realização desse trabalho.

\section{REFERÊNCIAS}

[1] W. E. Lee, R. E. Moore, Evolution of in situ refractories in the $20^{\text {th }}$ century, J. Am. Ceram. Soc. 81 (1998) 13851410.

[2] S. Mukhopadhyay, P. K. Das Poddar, Effect of preformed and in situ spinels on microstructure and properties of a low cement refractory castable, Ceram. Int. 30 (2004) 369-380.

[3] S. Zhang, W. E. Lee, Spinel-containing refractories, In: Refractories Handbook. Marcel Dekker Inc., EUA (2004)
215-258.

[4] M. Fuhrer,A.Hey ,W.E.Lee, Microstructural evolution in self-forming spinel/calcium aluminate castable refractories, J. Eur. Ceram. Soc. 18 (1998) 813-820.

[5] M. A. L. Braulio, D. H. Milanez, E. Y. Sako, L. R. M. Bittencourt, V. C. Pandolfelli, The effect of calcium aluminate cement on the in situ spinel formation. In: Proc. UNITECR'07, Dresden, Alemanha ( 2007) 540-543.

[6] M. A. L. Braulio, D. H. Milanez, E. Y. Sako, L. R. M. Bittencourt, V. C. Pandolfelli, Expansion behavior of cement-bonded alumina-magnesia refractory castables, Am. Ceram. Soc. Bull. 86, 12 (2007) 9201-9206.

[7] S. Itose, M. Nakashima, T. Isobe, I. Shimizu, Improvement in the durability of alumina-spinel steel ladle castable containing spinel fine powder, J. Tech. Assoc. Refract. 22 (2002) 26-30.

[8] M. Kobayahi, K. Kataoka, Y. Sakamoto, I. Kifune, Use of alumina-magnesia castable in steel ladle sidewalls, Taikabutsu Overseas 17, 3 (1997) 39-44.

[9] P. Nandi, A. Grag, B. D. Chattoraj, Y. Mukhopadhya, Effect of silica and temperature on spinel-based high-alumina castables, Am. Ceram. Soc. Bull. 79, 12 (2000) 65-69.

[10] G. Oprea, G. Ye, T. Troczynski, Sintering studies on binding systems for spinel bonded castable, In: Proc. UNITECR'05, Orlando, EUA (2005) 45-49.

[11] M. A. L. Braulio, D. H. Milanez, E. Y. Sako, L. R. M. Bittencourt, V. C. Pandolfelli, Are refractory aggregates inert?, Am. Ceram. Soc. Bull. 87, 3 (2008) 27-32.

[12] M. A. L. Braulio, L. R. M. Bittencourt, J. Poirier, V. C. Pandolfelli, Microssilica effects on cement bonded aluminamagnesia refractory castables, J . Tech. Assoc. Refract. 28, 3 (2008) 180.

[13] W. E. Lee, W. Vieira, S. Zhang , A. Ghanbari, H. Sarpoolaky, C. Parr, Castable Refractory Concretes, Int. Mater. Rev. 46, 3 (2001) 145-167.

[14] K. Ide, T. Suzuki, K. Asano, T. Nishi, T. Isobe, H. Ichikawa, Expansion behavior of alumina-magnesia castables, J. Tech. Assoc. Refract. 25, 3 (2005) 202-208.

(Rec. 25/03/2008, Ac. 18/07/2008) 